\title{
Multiobjective Stochastic Linear Programming: An Overview
}

\author{
A. Segun Adeyefa, Monga K. Luhandjula* \\ Department of Decision Sciences, University of South Africa, Pretoria, South Africa \\ E-mail:"luhanmk@unisa.ac.za \\ Received June 15, 2011; revised July 10, 2011; accepted July 29, 2011
}

\begin{abstract}
Many Optimization problems in engineering and economics involve the challenging task of pondering both conflicting goals and random data. In this paper, we give an up-to-date overview of how important ideas from optimization, probability theory and multicriteria decision analysis are interwoven to address situations where the presence of several objective functions and the stochastic nature of data are under one roof in a linear optimization context. In this way users of these models are not bound to caricature their problems by arbitrarily squeezing different objective functions into one and by blindly accepting fixed values in lieu of imprecise ones.
\end{abstract}

Keywords: Linear Programming, Multiobjective Programming, Stochastic Programming, Expected Value Optimality/Efficiency, Variance Optimality/Efficiency, Expected Value/Standard Deviation Efficiency, Tammer Optimality, Minimum Risk Optimality/Efficiency, Optimality/Efficiency in Probabilities

\section{Introduction}

Many concrete real life problems may be put into a Linear Programming framework (see e.g., [1-8]). For some of these problems, the Decision maker has to ponder conflicting objective functions. Such competing goals cannot be arbitrarily squeezed within the narrow framework of a unique objective function, without running the risk of invalidating all implications that are supposed to be drawn from the analysis. Simple examples (see e.g., [9-13]) are in line with the endorsed paradox [14] and the Arrow's impossibility Theorem [15], where there are no good ways of aggregating conflicting criteria into a single one. This has given rise to the field of Multiobjective Programming (MOP). For discussions on Multiobjective Programming problems, the reader may consult [16-21].

Over and above the presence of several conflicting goals, the above mentioned problems may involve some level of uncertainty about the values to be assigned to various parameters. In this connection the noted philosopher Nietzche was quoted as saying,

"No one is gifted with immaculate perception".

False certainty is bad science and it could be dangerous if it stunts articulation of critical choices. Interested readers are referred to [22-32] for problems where uncer- tainty should be accommodated in an optimization setting.

Uncertainty presents unique difficulties in constrained optimization problems, because the Decision makers are faced with doubtful situations, requiring an analysis of multiple outcomes in different states of nature. When the uncertainty in question is stochastic in nature, then we enter the field of Multiobjective Stochastic Linear Programming (MOSLP); the subject matter of this paper.

In such a turbulent environment, the notion of "optimum optimorum" no longer applies. One has, then, to resort to the notion of satisficing solution, based upon Simon's bounded rationality principle [33].

Methods for singling out a compromise solution in a MOSLP problem have been developed in the literature, leading to three main trends, namely: the hard, the soft and the metaheuristics. For the first trend, we refer the reader to [34-37]. For the second one, the reader may consult $[38,39]$. Examples of the third trend may be found in [40-42].

Within each group, the original problem may be either reduced to a single objective stochastic program (stochastic approach) or converted to a deterministic multiobjective program (multiobjective approach). A third alternative is to combine in an appropriate manner a technique of single objective Stochastic Programming with a technique 
of Multiobjective Programming (hybrid approach).

For the sake of space, this review focuses on the hard trend. An interested reader is referred to [43-47] where he may find details about the other two trends.

The methodological line followed in this overview consists of discussing upstream, existing solution concepts and placing extant results in a coherent and computational framework. Some existing applications are then listed downstream.

We also take a step towards comparing the approaches mentioned. Such a comparison may help in designing a Decision Support System for MOSLP. The above mentioned extension is outside the scope of the present paper, and has therefore, been left for further research.

Despite the purely mathematical nature of many works in the field of MOSLP as illustrated in [48-50], research in this field has been suggested by a specific class of concrete, real-life problems. Such a class of problems includes reservoir operation [51], coal mining [11], water resource management [52] and transportation planning [14].

The paper is organized as follows. In the next section, we give a mathematical formulation of the problem at hand and discuss related solution concepts. Section 3 deals with some mathematical results in connection with MOSLP. Section 4 is devoted to a discussion of methodological aspects of MOSLP along with a comparison of the above mentioned approaches. In Section 5, we point out some existing applications. We end with a number of concluding remarks along with suggestions for further developments in this field.

\section{Problem Formulation and Solution Concepts}

\subsection{Problem Formulation}

A Multiobjective Stochastic Linear Programming problem is a problem of the type:

$$
\min _{x \in D(\omega)}\left(c^{1}(\omega) x, \cdots, c^{K}(\omega) x\right)
$$

where

$$
D(\omega)=\left\{x \in \mathbb{R}^{n}: A(\omega) x \leq b(\omega) ; x \geq 0\right\}
$$

$c^{1}(\omega), \cdots, c^{K}(\omega)$ are $n$-dimensional random vectors defined on a probability space $(\Omega, \Gamma, \mathbb{P}), A(\omega)$ and $b(\omega)$ are respectively $m \times n$ and $m \times 1$ random matrices defined on the same probability space.

As an example of a concrete problem that may be put into the form of (1), we mention the automated manufacturing system in a production planning situation, with several objective functions, where the costs and time of production are known only stochastically [53].
For other problems that may be modelled in the same way as (1), we may mention reconfigurable manufacturing systems [40], distributed energy resources planning [54], water use planning [55], manufacturing planning [56], power systems planning [57-59] energy and reserves markets [60] and multi-product batch plant design [61].

Owing to the presence of conflicting goals and the randomness surrounding data, the mathematical program described in (1) is an ill-stated problem. Therefore, neither the notion of feasibility nor that of optimality is clearly defined for this problem. One, then, has to resort to the Simon's bounded rationality principle [33] and seek for a satisficing solution instead of an optimal one.

Before discussing some existing solution concepts for this problems along with some related mathematical results and methodological approaches, let us attempt to provide some meaning to problem (1).

\subsection{Transformation of the Feasible Set}

One generally transform $D(\omega)$ to a deterministic set, say $D$ according to the rules used in Stochastic Programming (see e.g. [62-64]).

Some commonly used deterministic counterparts of $D(\omega)$ are listed below:

1) $D^{\prime}=\left\{x \in \mathbb{R}^{n}: E(A(\omega)) x \leq E(b(\omega)) ; x \geq 0\right\}$

where $E$ stands for the expected value.

2) $D^{\prime \prime}(\alpha)=\left\{x \in \mathbb{R}^{n}: P(A(\omega) x \leq b(\omega)) \geq \alpha ; x \geq 0\right\}$

where $\alpha$ is a probability level pre-defined by the Decision maker.

3) $D^{\prime \prime \prime}\left(\alpha_{1}, \cdots, \alpha_{m}\right)=\bigcap_{i=1}^{m} D_{i}\left(\alpha_{i}\right)$ where for each fixed $i=\{1, \cdots, m\}$

$$
D_{i}\left(\alpha_{i}\right)=\left\{x \in \mathbb{R}^{n}: P\left(A_{i}(\omega) x \leq b_{i}(\omega)\right) \geq \alpha_{i}, x \geq 0\right\}
$$

here $\alpha_{i}$ are probability levels a-priori fixed by the Decision maker and $A_{i}(\omega), b_{i}(\omega)$ are respectively the $i^{\text {th }}$ row of $A(\omega)$ and the $i^{\text {th }}$ component of $b(\omega)$.

$$
\text { 4) } D^{i v}=\left\{x \in \mathbb{R}^{n}: Q(x, \omega)<+\infty \text {, with probability } 1\right\}
$$

where

$$
Q(x, \omega)=\left\{\begin{array}{cl}
\text { inf } q(\omega) y \\
y \in \Upsilon & \text { if } \Upsilon \neq \varnothing \\
+\infty ; & \text { if } \Upsilon=\varnothing
\end{array}\right.
$$

where $q(\omega)$ is a penalty cost, $W(\omega)$ is a recourse matrix and

$$
\Upsilon=\left\{y \in \mathbb{R}^{m}: W(\omega) y=b(\omega)-A(\omega) x ; y \geq 0\right\}
$$

In the next section, we discuss some existing solution 
concepts for MOSLP problems.

\section{Solution Concepts for Multiobjective Stochastic Linear Programming Problems}

To avoid complications unrelated to our subject, we assume that involved random data have known distributions with finite expected values and variances.

\subsection{Expected Value and Variance Optimalities}

Consider the following deterministic mathematical programs:

$$
\begin{aligned}
& \min _{x \in D} E(c(\omega)) x \\
& \min _{x \in D} V(c(\omega)) x
\end{aligned}
$$

with $E$ and $V$ denoting the expected value and the variance respectively.

Definition 3.1 If $x^{*}$ is an optimal solution for Program (2), ((3)) then $x^{*}$ is called an expected value ( $a$ variance) optimal solution for problem (1), when $D$ is a transformation of $D(\omega)$ obtained through technique of stochastic optimization.

Where $c(\omega)$ is an aggregation of $c^{1}(\omega), \cdots, c^{K}(\omega)$ based on techniques of multiattribute utility theory [65].

From now on $\psi_{E}$ and $\psi_{V}$ stand respectively for the set of expected value and variance optimal solutions for problem (2).

A shortcoming of the above defined solution concepts is that, the expected value and the variance do not exhaust the information contained in the distributions of involved random variables [34]. To overcome this drawback, other solution concepts have been proposed. We discuss some of them in the next three subsections.

\subsection{Tammer and Minimum Risk Optimalities and Optimality in Probability}

Definition $3.2 x^{*}$ is a Tammer $\alpha$-optimal solution for Problem (1), if there is no $x \in D$ such that

$$
P\left(\omega: c(\omega) x \leq c(\omega) x^{*}\right) \geq 1-\alpha
$$

and

$$
P\left(\omega: c(\omega) x<c(\omega) x^{*}\right)>0
$$

when $D$ is a transformation of $D(\omega)$ obtained through technique of stochastic optimization. Here $\alpha$ is a probability level pre-defined by the Decision maker.

For details on this solution concept, we invite the reader to consult [66].

Definition $3.3 x^{*}$ is an $\alpha$-minimum risk optimal solution for Problem (1), if $x^{*}$ is an optimal solution for the following program:

$$
\max _{x \in D} P(c(\omega) x \leq \alpha)
$$

when $D$ is a transformation of $D(\omega)$ obtained through technique of stochastic optimization. Where $\alpha$ is an aspiration level a-priori fixed by the Decision maker.

An interested reader is referred to [67] for key facts about the minimum risk solution concept.

Definition $3.4 x^{*}$ is a $\rho$-optimal solution in probability for Problem (1), if there is $\beta^{*} \in \mathbb{R}$ such that $\left(x^{*}, \beta^{*}\right)$ is optimal for the program:

$$
\begin{aligned}
& \min _{(x, \beta) \in D \times \mathbf{R}} \beta \\
& \text { subject to } \\
& P(c(\omega) x \leq \beta)=\rho
\end{aligned}
$$

when $D$ is a transformation of $D(\omega)$ obtained through technique of stochastic optimization. Where $\rho$ is a probability level pre-defined by the Decision maker.

A reader interested to know more about this solution concept is referred to [68].

\subsection{Expected Value and Variance Efficiencies}

Consider the following deterministic multiobjective programs:

$$
\begin{gathered}
\min _{x \in D}\left\{E\left(c^{1}(\omega)\right) x, \cdots, E\left(c^{K}(\omega)\right) x\right\} \\
\min _{x \in D}\left\{V\left(c^{1}(\omega)\right) x, \cdots, V\left(c^{K}(\omega)\right) x\right\} \\
\min _{x \in D}\left\{E\left(c^{1}(\omega)\right) x, \cdots, E\left(c^{K}(\omega)\right) x, \sigma\left(c^{1}(\omega)\right) x, \cdots,\right. \\
\left.\sigma\left(c^{K}(\omega)\right) x\right\}
\end{gathered}
$$

where $\sigma$ stands for the standard deviation.

Definition $3.5 x^{*}$ is called an expected value, a variance or an expected value/standard deviation efficient solution for problem (1), If $x^{*}$ is efficient for Programs (6), (7) or (8) respectively, when $D$ is a transformation of $D(\omega)$ obtained through technique of stochastic optimization.

The sets of expected value, variance and expected value/standard deviation efficient solutions for Program (1) are denoted by $\varphi_{E}, \varphi_{V}$ and $\varphi_{E / \sigma}$ respectively.

The concept of expected value weak efficiency, variance weak efficiency and expected value/standard deviation weak efficiency and those of expected value proper efficiency, variance proper efficiency and expected value/standard deviation proper efficiency are obtained by replacing "efficiency" by "weak efficiency" and by "proper efficiency" respectively. 
In the sequel $\varphi_{E}^{w}\left(\phi_{E}^{p}\right), \varphi_{E}^{p}\left(\varphi_{V}^{p}\right)$ and $\varphi_{E / \sigma}^{w}\left(\varphi_{E / \sigma}^{p}\right)$ denote the sets of expected value weakly (properly) efficient solutions, variance weakly (properly) efficient solutions and expected value/standard deviation weakly (properly) efficient solutions for program (1) respectively.

\subsection{Minimum Risk Efficiency and Efficiency in Probabilities}

Minimum risk efficiency is defined as follows.

Definition $3.6 x^{*}$ is an $\left(\alpha_{1}, \cdots, \alpha_{K}\right)$-minimum risk efficient solution for problem (1), if $x^{*}$ is efficient for the multiobjective program:

$$
\max _{x \in D}\left\{P\left(c^{1}(\omega) x \leq \alpha_{1}\right), \cdots, P\left(c^{K}(\omega) x \leq \alpha_{K}\right)\right\}
$$

when $D$ is a transformation of $D(\omega)$ obtained through technique of stochastic optimization. Here $\left(\alpha_{1}, \cdots, \alpha_{K}\right)$ are aspiration levels $a$-priori fixed by the Decision maker.

Characterizations of minimum risk efficiency with aspiration levels, may be found elsewhere [69].

As in the case of expected value efficiency, the concepts of $\left(\alpha_{1}, \cdots, \alpha_{K}\right)$-minimum risk weak efficiency and $\left(\alpha_{1}, \cdots, \alpha_{K}\right)$-minimum risk proper efficiency may be obtained by respectively replacing "efficiency" by "weak efficiency" or "proper efficiency" in the above definition.

In what follows $\psi_{M R}\left(\alpha_{1}, \cdots, \alpha_{K}\right), \psi_{M R}^{w}\left(\alpha_{1}, \cdots, \alpha_{K}\right)$ and $\psi_{M R}^{p}\left(\alpha_{1}, \cdots, \alpha_{K}\right)$ denote the sets of $\left(\alpha_{1}, \cdots, \alpha_{K}\right)$ minimum risk efficient solutions, $\left(\alpha_{1}, \cdots, \alpha_{K}\right)$-minimum risk weakly efficient solutions and $\left(\alpha_{1}, \cdots, \alpha_{K}\right)$ minimum risk properly efficient solutions for Program (1) respectively.

For efficiency with given probabilities we give the following definition.

Definition $3.7 x^{*}$ is a $\left(\rho_{1}, \cdots, \rho_{K}\right)$-efficient solution in probability for problem (1), if there is

$\beta^{*}=\left(\beta_{1}^{*}, \cdots, \beta_{K}^{*}\right)$ such that $\left(x^{*}, \beta^{*}\right)$ is efficient for the mathematical program:

$$
\begin{aligned}
& \min _{(x, \beta) \in D \times \mathbf{R}}\left(\beta_{1}, \cdots, \beta_{K}\right) \\
& \text { subject to } \\
& P\left(c^{k}(\omega) x \leq \beta_{k}\right) \geq \rho_{k}, k=1, \cdots, K
\end{aligned}
$$

when $D$ is a transformation of $D(\omega)$ obtained through technique of stochastic optimization. Where $\rho_{1}, \cdots, \rho_{K}$ are probability levels that are a-priori fixed by the Decision maker.

An interested reader may consult [14] for a thorough discussion on this efficiency concept.

Concepts of $\left(\rho_{1}, \cdots, \rho_{K}\right)$-weak efficiency in probability and $\left(\rho_{1}, \cdots, \rho_{K}\right)$-proper efficiency in probability may also be obtained in a way similar to the one in which minimum risk weak and proper efficiencies were obtained.

From now on $\psi_{K T}\left(\rho_{1}, \cdots, \rho_{K}\right), \psi_{K T}^{w}\left(\rho_{1}, \cdots, \rho_{K}\right)$ and $\psi_{K T}^{P}\left(\rho_{1}, \cdots, \rho_{K}\right)$ denote the sets of $\left(\rho_{1}, \cdots, \rho_{K}\right)$-efficient solutions in probability, $\left(\rho_{1}, \cdots, \rho_{K}\right)$-weakly efficient solutions in probability and $\left(\rho_{1}, \cdots, \rho_{K}\right)$ properly efficient solutions in probability for Program (1) respectively.

In the next section we present some theoretical results related to problem (1).

\section{Related Mathematical Results}

Most stochastic constraint transformations yield nonconvexity on resulting deterministic feasible sets. This precludes the application of existing powerful convex optimization algorithms (see e.g. [70,71]). It is therefore, relevant to know when a deterministic counterpart of $D(\omega)$ is convex. The following four propositions; the proofs of which may be found in [72], provide some insights to this issue.

Proposition 4.1 $D^{\prime \prime}(0), D^{\prime \prime}(1), D_{i}(0) ; i=1, \cdots, m$, $D_{i}(1) ; i=1, \cdots, m$ and $D^{i v}$ are convex sets.

Proposition 4.2 Consider Problem (1) and suppose that $A(\omega)$ is a fixed matrix with maximal rank. Then

$$
D_{i}\left(\alpha_{i}\right)=\left\{x \in \mathbb{R}^{n}: F_{i}\left(A_{i} x\right) \geq \alpha_{i} ; i=1, \cdots, m\right\}
$$

are convex for every probability distribution $F_{i}$ of $b_{i}(\omega)$.

Proposition 4.3 Assume that the probability space under consideration is discrete, that is, $\Omega=\left\{\omega_{1}, \cdots, \omega_{L}\right\}$ and $P\left(\omega_{l}\right)=p_{l}>0, l=1, \cdots, L$. Let

$\alpha_{l}^{*}=\max \left(1-p_{l}: 1 \leq l \leq L\right)$ then the set $D_{l}\left(\alpha_{l}\right)$ is convex for any $\alpha_{1}>\alpha_{1}^{*}$ and $D^{\prime \prime}(\alpha)$ is convex for any $\alpha>\alpha^{*}$, where $\alpha^{*}$ and $\alpha_{1}^{*}$ are real numbers.

Proposition 4.4 Suppose that the probability space under consideration is $\Omega=\left\{\omega_{1}, \cdots, \omega_{L}\right\}$ and suppose that $p_{l}=P\left(\omega_{l}\right)>0$ if and only if $l \in N=\{1, \cdots, r\}$. Assume also that only one element $l_{o} \in N$ exists such that

$$
p_{l_{o}}=\min _{l \in N} p_{l},
$$

then the sets $D^{\prime \prime}(\alpha)$ and $D_{l}^{\prime \prime}(\alpha)$ are convex for every $\alpha>1-p_{l_{1}}$ where

$$
p_{l_{1}}=\min _{l \in\left(N \backslash\left\{l_{0}\right\}\right)} p_{l} .
$$

The next two results established in [73,74], bridge the gap between solution concepts based on the first two moments (Proposition 4.5) and establish a connection between a minimum risk efficient solution with aspiration levels and an efficient solution with given probabilities (Proposition 4.6).

Proposition 4.5

$$
\text { 1) } \varphi_{E} \bigcap \varphi_{V} \subset \varphi_{E / \sigma}
$$




$$
\begin{aligned}
& \text { 2) } \varphi_{E} \cup \varphi_{V} \subset \varphi_{E / \sigma}^{w} \\
& \text { 3) } \varphi_{E}^{w} \cup \varphi_{V}^{w} \subset \varphi_{E / \sigma}^{w}
\end{aligned}
$$

Proposition 4.6 Assume that the probability distributions of the random vectors $c^{1}(\omega), \cdots, c^{K}(\omega)$ are continuous and strictly increasing. Then for any $\left(\alpha_{1}, \cdots, \alpha_{K}\right) \in \mathbb{R}^{K}, x^{*} \in \psi_{M R}\left(\alpha_{1}, \cdots, \alpha_{K}\right)$ if and only if $x^{*} \in \psi_{K T}\left(\rho_{1}, \cdots, \rho_{K}\right)$, where

$$
\rho_{k}=P\left(c^{k}(\omega) x \leq \alpha_{k}\right) ; k \in\{1, \cdots, K\}
$$

Moreover, we have:

\section{Proposition 4.7}

$$
\bigcup_{\left(\alpha_{1}, \cdots, \alpha_{K}\right) \in R^{K}} \psi_{M R}\left(\alpha_{1}, \cdots, \alpha_{K}\right)=\bigcup_{\left(\rho_{1}, \ldots, \rho_{K}\right) \in B} \psi_{K T}\left(\rho_{1}, \cdots, \rho_{K}\right)
$$

with

$$
B=\left\{\left(\rho_{1}, \cdots, \rho_{K}\right): \rho_{k} \in(0,1] ; k=1, \cdots, K\right\}
$$

Well-known characterizations of proper efficiency have been explored to relate optimality and efficiency of program (1). This is the subject matter of the next two propositions.

Proposition 4.8 If $x^{*}$ is an expected value optimal solution for problem (2), then $x^{*}$ is an expected value properly efficient solution for program (6). That is,

$$
\psi_{E} \subseteq \varphi_{E}^{P}
$$

Proposition 4.9 If $D$ is a convex set and $E\left(c^{k}(\omega)\right) x ; k=1, \cdots, K$ are convex functions, then $x^{*}$ is an expected value properly efficient solution for the multiobjective program (6), if and only if, $x^{*}$ is an expected value optimal solution for the problem (2). That is,

$$
\varphi_{E}^{P}=\psi_{E}
$$

An interested reader is referred to [14] for more details on this matter.

\section{Methodological Approaches for Solving Multiobjective Stochastic Linear Programs}

The ideas discussed in the previous sections have served as guidelines in implementing efficient techniques for solving Multiobjective Stochastic Linear Programming problems.

In what follows we outline a method within each of the three existing approaches namely, the stochastic approach, the multiobjective approach and the hybrid one.

\subsection{Stochastic Approach}

In this section we present a method described in [38] for solving problem (1), using the stochastic approach. For this method the following assumptions should be met: $A_{i}(\omega), \quad i=1, \cdots, m ; \quad b(\omega)$ and $c^{k}(\omega), \quad k=1, \cdots, K$ are normally distributed random vectors. $\lambda_{k}$,

$k=1, \cdots, K$ are strictly positive real numbers in the interval $(0,1]$ such that $\sum_{k=1}^{K} \lambda_{k}=1$.

Moreover, the following notations are used:

1) $h_{i}(\omega, x)=A_{i}(\omega) x-b_{i}(\omega), \quad i=1, \cdots, m$.

2) $\Phi$ denotes the cumulative distribution function of the standard normal random variable.

3) $q_{1}$ and $q_{2}$ are weights associated with the expected value and the standard deviation of $c(\omega)$ respectively.

4) $\alpha=\left(\alpha_{1}, \cdots, \alpha_{m}\right)$ where $\alpha_{i}, \quad i=1, \cdots, m$ are probability levels prescribed by the Decision maker for constraints satisfaction.

A stepwise description of the method is as follows:

Step 1. Read $\lambda_{k}, k=1, \cdots, K ; c^{k}(\omega), k=1, \cdots, K$; $h_{i}(\omega, x), i=1, \cdots, m ; \quad \alpha_{i}, i=1, \cdots, m$

Step 2. Find

$$
c(\omega)=\sum_{k=1}^{K} \lambda_{k} c^{k}(\omega)
$$

Step 3. Replace $D(\omega)$ by

$$
\begin{aligned}
D^{v}=\{ & x \in R^{n}: E\left(h_{i}(\omega, x)\right) \\
& \left.+\Phi^{-1}\left(\alpha_{i}\right) \sigma\left(h_{i}(\omega, x)\right) \leq 0, i=1, \cdots, m ; x \geq 0\right\}
\end{aligned}
$$

Step 4. Solve the mathematical program:

$$
\min _{x \in D^{v}}\left(q_{1} E(c(\omega))+q_{2} \sigma(c(\omega))\right)
$$

Let $x^{*}$ be a solution of (11).

Step 5. Stop.

As can be seen, this algorithm transforms the original problem into a single objective problem, that has been put in the deterministic form (11), using the expected value model approach [63].

The solution $x^{*}$ obtained is an expected value/standard deviation efficient solution for problem (1) as defined in $\$ 3.1$.

Other techniques closely related to the stochastic approach for solving problem (1) include, decomposition method [75-77], chance-constrained method [4,78], simulation based techniques [79-81], two stage method [61] and multistage method [82].

\subsection{Multiobjective Approach}

Here we outline a method within the multiobjective approach. For this method, we need $\lambda_{k}, k=1, \cdots, K$; such that $\lambda_{k}>0, \quad \sum_{k=1}^{K} \lambda_{k}=1$ as in $\S 5.1$. 
The steps of the method are as follow:

Step 1. Read $\lambda_{k}, k=1, \cdots, K ; c^{k}(\omega), k=1, \cdots, K$; $A(\omega) ; b(\omega)$.

Step 2. Replace $D(\omega)$ by

$$
D^{\prime}=\left\{x \in R^{n}: E(A(\omega)) x-E(b(\omega)) \leq 0 ; x \geq 0\right\}
$$

Step 3. Find:

$$
E\left(c^{1}(\omega)\right), \cdots, E\left(c^{K}(\omega)\right)
$$

Step 4. Solve the mathematical program:

$$
\min _{x \in D^{\prime}}\left(\sum_{k=1}^{K} \lambda_{k} E\left(c^{k}(\omega)\right) x\right)
$$

Let $x^{*}$ be a solution of (13)

Step 5. Stop.

In this method, Steps 2 and 3 tackle randomness, while Step 4 deals with multiplicity of objective functions. The solution $x^{*}$ obtained is an expected value efficient solution for MOSLP problem (1) as defined in §3.3.

For a more thorough discussion of other methods for solving MOSLP problem (1) based on the multiobjective approach, the reader is referred to [83-89].

\subsection{Hybrid Approach}

In this section, we describe a hybrid method due to [90], for solving MOSLP problem (1). This method is based on the assumptions given in $\S 5.1$. The following notations are used in the sequel.

1) $\delta_{s}^{+}, s=1, \cdots, S ; \delta_{t}^{-}, t=1, \cdots, T ; \delta_{u}^{+}, \delta_{u}^{-}$, $u=1, \cdots, U$ denote positive, negative and two sided deviations from targets $g_{s}, s=1, \cdots, S ; g_{t}$,

$t=1, \cdots, T ; g_{u}, u=1, \cdots, U$ respectively. $S, T$ and $U$ are respectively the total number of positive, negative and two-sided deviations from targets $g_{s}, g_{t}$ and $g_{u}$.

2) $\alpha_{s}, s=1, \cdots, S ; \alpha_{t}, t=1, \cdots, T ; \alpha_{u}$,

$u=1, \cdots, U$ are probability levels a-priori fixed by the Decision maker.

Here are the steps of the method.

Step 1. Read $S, T, U, g_{s}, \alpha_{s}, s=1, \cdots, S ; g_{t}$, $\alpha_{t}, t=1, \cdots, T ; g_{u}, \alpha_{u}, u=1, \cdots, U ; c^{k}(\omega)$, $k=1, \cdots, K ; h_{i}(\omega, x), i=1, \cdots, m$

Step 2. Put $D(\omega)$ in the following form:

$$
\begin{aligned}
D^{v i}=\{ & x \in \mathbb{R}^{n}: E\left(c^{s}(\omega)\right) x \\
& +\Phi^{-1}\left(\alpha_{s}\right) \sigma\left(c^{s}(\omega)\right) x-g_{s}-\delta_{s}^{+} \leq 0, \\
& s=1, \cdots, S ; E\left(c^{t}(\omega)\right) x \\
& +\Phi^{-1}\left(1-\alpha_{t}\right) \sigma\left(c^{t}(\omega)\right) x-g_{t}+\delta_{t}^{+} \leq 0, \\
& t=1, \cdots, T ; E\left(c^{u}(\omega)\right) x \\
& +\Phi^{-1}\left(\frac{1-\alpha_{u}}{2}\right) \sigma\left(c^{k}(\omega)\right) x-g_{u} \leq 0
\end{aligned}
$$

$$
\begin{aligned}
& u=1, \cdots, U ; E\left(h_{i}(\omega, x)\right) \\
& +\Phi^{-1}\left(\alpha_{i}\right) \sigma\left(h_{i}(\omega, x)\right) \leq 0 \\
& \left.i=1, \cdots, m ; \delta_{s}^{+} \geq 0, \delta_{t}^{+} \geq 0, x \geq 0\right\}
\end{aligned}
$$

Step 3. Solve the mathematical program:

$$
\min _{x \in D^{v i}}\left(\sum_{u=1}^{U}\left(\delta_{u}^{+}+\delta_{u}^{-}\right)+\sum_{s=1}^{S} \delta_{s}^{+}+\sum_{t=1}^{T} \delta_{t}^{-}\right)
$$

Let $x^{*}$ be a solution of (14).

Step 4. Stop.

It is clear that this method combines the goal programming technique for solving a multiobjective program with the chance-constrained method for solving a stochastic optimization problem.

Other methods pertaining to the hybrid approach may be found in [91-93].

\subsection{Comparison of Different Approaches}

The main lessons that can be drawn while comparing the above described approaches outlined above are as follow:

1) The stochastic approach takes into account dependencies between objective functions, whereas the multiobjective approach does not (see for example [94]). This makes the stochastic approach closer to reality. Therefore, the stochastic approach is more effective for finding solutions to a MOSLP problem than the multiobjective approach.

2) The multiobjective approach is more efficient than the stochastic approach, in the sense that it requires fewer computations. These computations are easier to handle than those required by the stochastic approach. (see e.g., $[49,58,95])$.

3) The hybrid approach combines the strengths of the stochastic and the multiobjective approaches. Consequently, the hybrid approach could perform better than either of the other two approaches for a given problem. Interested readers may consult [96] for a substantiation of this claim.

4) Methods pertaining to the hybrid approach create more flexibility in allowing the Decision maker to specify his preferences (see e.g., [91]).

Nevertheless, it is the nature and the structure of the problem that determines which approach to use.

In what follows, we briefly discuss some applications of Multiobjective Stochastic Linear Programming to concrete real-life problems.

\section{Applications}

\subsection{Applications of the Stochastic Approach}

Production planning problems, lend themselves better to 
the use of the stochastic approach. As a matter of fact, the structure of these problems dictates that one starts dealing with the multiplicity of objective functions and later tackles the randomness in data [97].

Some other applications of the stochastic approach to MOSLP problems include power system security problem [98], power plant preventive maintenance scheduling [75], capacity planning [99], hydro-thermal electricity generation [100], deployment of roadway incident response vehicles [101] and multi-product batch plant design [61].

\subsection{Applications along the Multiobjective Approach}

Water resource planning and management problems [86], are most appropriately dealt with using the multiobjective approach. Random parameters are first transformed into appropriate fixed data, before the conflicting goals are sorted out. The literature is rich in models using the multiobjective approach. We list a few of them:

Water use planning [55], workforce scheduling model [102], transportation network design problem [85] and nuclear generation of electricity problem [57,103].

\subsection{Applications within the Hybrid Approach}

To significantly bridge the dangerous gap between the problems of designing reliable portfolio assets and the mathematical programming models used to solve them, the Decision maker should be able to consider different objective functions and incorporate imprecision into the model. Owing to the complexity of such problems, it is best to couple different techniques in an appropriate way to solve them.

There are several good papers using this approach, to which the reader may refer. The papers [96,104-109] are some of them.

\section{Concluding Remarks}

Multiobjective Stochastic Linear Programming is a worthwhile topic. It provides a glimpse into what it means to jostle with the complicated issue (which is nevertheless useful for applications) of combining randomness and multiplicity of objectives into an optimization setting. Methods described in this field are valuable resources for those facing optimization problems involving conflicting goals and random parameters and wishing not to caricature the underlying problem by blindly replacing it with a traditional (deterministic) optimization problem.

Paraphrasing Howard [110], the scientific approach to decision making and problem solving has demonstrated that, it can provide efficient tools to those few who have the resources and the will to use it. The new challenge is to provide this help at an affordable price to all who could benefit from it.

There is a rich array of methods that can be used to deal with both Multiobjective Programming and Stochastic Programming problems. This paper has somewhat demonstrated that, the Howards view applies to Multiobjective Stochastic Programing. Nevertheless, theoretical and computational issues, along with the meaning of introduced solution concepts, play a crucial role in such a turbulent environment.

In this paper we have presented the main principle of MOSLP. We have also indicated that there are concrete realizations in this field. We have also discussed opportunities and limitations of MOSLP. To cater best for a broad readership, the paper has the following distinctive features:

1) It is organized towards the technique-oriented format in contrast to the theoretically speculative one.

2) Practical aims take precedence over mathematical niceties.

3) The basic ideas (solution concepts, related mathematical results, methodological aspects and applications) have been presented in an understandable manner.

4) The paper is filled with references for those whose appetite have been sufficiently wetted.

Kirby [111] has argued that the main objections against Operation Research techniques are as follows:

1) Operation Research techniques ignore managerial needs (perversion criticism).

2) Operation Research methods have already been used wherever they were needed (obsolescence criticism).

3) Management needs have evolved and are more complex than those which Operation Research caters for (inadequacy criticism).

4) Operation Research's practice has been misguided and has undermined the confidence managers had in it (counter-performance criticism).

This paper makes some contributions towards remedying the above mentioned perversion and inadequacy objections.

Among lines for further developments in this field we may mention:

1) Extension of the theory and methods outlined here to the nonlinear cases.

2) Comparison of Multiobjective Stochastic Linear Programming with Multiobjective Fuzzy Linear Programming [28,50,112].

3) Design of a user-friendly Decision Support System for Multiobjective Programming under uncertainty.

4) Incorporation of both randomness and fuzziness 
into a multiobjective optimization context [113].

5) Development of Intelligent Hybrid Algorithms for tackling these complex optimization problems.

Let us hope that successful developments in the above mentioned directions will proceed in the near future, thus reducing the gaps between the language used in Multiobjective Stochastic Programming techniques and the language used by potential users of these techniques.

\section{References}

[1] A. Andreas and L. Wu-Sheng, "Practical Optimization: Algorithm and Engineering Applications," Springer, New York, 2007.

[2] D. W. Bunn, “Applied Decision Analysis," McGraw Hill, New York, 1984.

[3] A. Charnes and W. W. Cooper, "Chance-Constrained Programming," Management Sciences, Vol. 6, No. 1, 1959, pp. 73-79. doi:10.1287/mnsc.6.1.73

[4] A. Charnes and W. W. Cooper, "Management Models and Industrial Applications of Linear Programming," John Wiley and Sons Inc., New York, Vol. 1, 1961.

[5] B. S. Gottfried and J. Weisman, "Introduction to Optimization Theory," Prentice-Hall Inc., Englewood, 1973.

[6] D. G. Luenberger, "Introduction to Linear and Nonlinear Programming," Addison-Wesley, Menlo Park, 1984.

[7] S. S. Rao, "Optimization Theory and Applications," 2nd Edition, John Wiley and Sons Inc., New York, 1984.

[8] S. S. Rao, "Engineering Optimization: Theory and Practice," 3rd Edition, John Wiley \& Sons Inc., New York, 1996.

[9] M. Ehrgott, "A Discussion of Scalarization Techniques for Multiobjective Integer Programming," Annals of Operations Research, Vol. 147, No. 1, 2006, pp. 343-360. doi:10.1007/s10479-006-0074-Z

[10] H. A. Eiselt, G. Pederzoli and C.-L. Sandblom, "Continuous Optimization Models," Walter deGruyter and Company, Berlin, 1987.

[11] A. Goicoechea, D. R. Hansen and L. Duckstein, "Multiobjective Decision Analysis with Engineering and Business Application," John Wiley and Sons Inc., New York, 1982.

[12] J. P. Ignizio, "Linear Programming in Single- and Multiple-objective Systems," Prentice-Hall Inc., Englewood Cliffs, 1982.

[13] M. Zeleny, "A Concept of Compromise Solutions and the Method of the Displaced Ideal," Computers and Operations Research, Vol. 1, No. 3-4, 1974, pp. 479-496. doi:10.1016/0305-0548(74)90064-1

[14] I. M. Stancu-Minasian, "Stochastic Programming with Multiple Objective Functions," D. Reidel Publishing Company, Dordrecht, 1984.

[15] K. J. Arrow, "A Difficulty in the Concept of Social Welfare," Journal of Political Economy, Vol. 58, No. 4, 1950, pp. 328-346. doi:10.1086/256963

[16] M. Ehrgott, "Multicriteria Optimization," 2nd Edition, Springer-Verlag, Berlin, 2005.

[17] J. Jahn, "Vector Optimization: Theory, Applications and Extensions," Springer-Verlag, Berlin, 2004.

[18] K. M. Miettinen, "Nonlinear Multiobjective Optimization," Kluwer Academic Publishers, Boston, 1999.

[19] B. Rustem, "Algorithms for Nonlinear Programming and Multiple-Objective Decisions," John Wiley and Sons Inc., New York, 1998.

[20] R. D. Shapiro, “Optimization Models for Planning \& Allocation: Text \& Cases in Mathematical Programming," Wiley \& Sons Inc., New York, 1984.

[21] M. Zeleny, "Multiple Criteria Decision Making," SpringerVerlag, Berlin, 1976.

[22] A. S. Adeyefa and M. K. Luhandjula, "Risk Management in Multiobjective Programming under Uncertainty for Managing Sustainable Development," First UNISA SBL 2010 International Conference on Leadership and Management for Sustainable Development, Johannesburg, 6-8 October 2010.

[23] S. B. Graves and J. L. Ringuest, "Probabilistic Dominance Criteria for Comparing Uncertain Alternatives: A Tutorial," Omega, Vol. 37, No. 2, 2009, pp. 346-357. doi:10.1016/j.omega.2007.03.001

[24] B. Liu, "Theory and Practice of Uncertainty Programming," Physica-Verlag, Heidelberg, 2002.

[25] M. K. Luhandjula, "Multiple Objective Programming Problems with Possibilistic Coefficients," Fuzzy Sets \& Systems, Vol. 21, No. 2, 1987, pp. 135-145. doi:10.1016/0165-0114(87)90159-X

[26] M. K. Luhandjula, "Fuzzy Optimization: An Appraisal," Fuzzy Sets \& Systems, Vol. 30, No. 3, 1989, pp. 257-282. doi:10.1016/0165-0114(89)90019-5

[27] M. K. Luhandjula, S. S. Ruzibiza and A. S. Adeyefa, "Solving Multiobjective Programming Problems with Fuzzy Coefficients," Advances in Fuzzy Sets \& Systems, Vol. 8, 2011, pp. 13-33.

[28] M. K. Luhandjula and M. Sakawa, "Multiple-Objective Linear Programming Problems in the Presence of Fuzzy Coefficients," In: R. Slowinski and J. Teghem, Eds., Stochastic versus Fuzzy Approaches to Multiobjective Mathematical Programming under Uncertainty, Kluwer Academic Publishers, Dordrecht, 1990. doi:10.1007/978-94-009-2111-5 15

[29] R. B. Porta, "A Comparison of Stochastic Dominance \& Stochastic Programming," Omega, Vol. 2, No. 1, 1974, pp. 105-117.

[30] A. D. Roy, "Safety First \& the Holding of Assets," Econometrica, Vol. 20, No. 3, 1952, pp. 431-449. doi:10.2307/1907413

[31] S. Vadja, "Probabilistic Programming," Academic Press, New York, 1972.

[32] H.-J. Zimmerman, "Description and Optimization of Fuzzy Systems," International Journal of General Sys- 
tems, Vol. 2, No. 4, 1976, pp. 209-215. doi: $10.1080 / 03081077608547470$

[33] H. Simon, "A Behavioral Model of Rational Choice in Models of Man, Social and Rational," Macmillan, New York, 1957.

[34] A. S. Adeyefa, "Methodological Approaches for Multiobjective Stochastic Linear Programmimg Problems," IFORS Conference, Sandton, 13-19 July 2008.

[35] H. Levy and J. Paroush, "Multiperiod Stochastic Dominance," Management Science, Vol. 21, No. 4, 1974, pp. 428-435. doi: $10.1287 / \mathrm{mnsc} .21 .4 .428$

[36] M. K. Luhandjula, A. S. Adeyefa and S. Mukeru, "Satisficing Solutions for Multiobjective Stochastic Linear Programming Problems," Submitted, 2011.

[37] D. Panda, S. Kar, K. Maity and M. Maiti, "A Single Period Inventory Model with Imperfect Production and Stochastic Demand under Chance and Imprecise Constraints," European Journal of Operational Research, Vol. 188, No. 1, 2008, pp. 121-139. doi:10.1016/j.ejor.2007.04.009

[38] S. Hulsurkar, M. P. Biswal and S. B. Sinha, "Fuzzy Programming Approach to Multi-Objective Stochastic Linear Programming Problem," Fuzzy Sets and Systems, Vol. 88, No. 2, 1997, pp. 173-181. doi:10.1016/S0165-0114(96)00056-5

[39] S. B. Sinha, S. Hulsurkar and M. P. Biswal, "Fuzzy Programming Approach to Multi-Objective Stochastic Programming Problems When Bi's Follow Joint Normal Distribution," Fuzzy Sets and Systems, Vol. 109, No. 1, 2000, pp. 91-96. doi:10.1016/S0165-0114(98)00070-0

[40] M. Abbasi and M. Houshmand, "Production Planning and Performance Optimization of Reconfigurable Manufacturing Systems Using Genetic Algorithm," International Journal of Advanced Manufacturing Technology, Vol. 54, No. 14, 2010, pp.373-392.

[41] X. R. Gandibleux, M. Sevaux, K. Sörensen and V. Tkindt, "Metaheuristics for Multiobjective Optimization," Springer-Verlag, Berlin, 2004.

[42] T. Ibaraki, K. Nonobe and M. Yagiura, "Metaheuristics: Progress as Real Problem Solvers," Springer, New York, 2005.

[43] K. F. Doerner, W. J. Gutjahr, R. F. Hartle and C. Strauss, "Nature-Inspired Metaheuristics for Multiobjective Activity Crashing," Omega, Vol. 36, No. 6, 2008, pp. 10191037. doi:10.1016/i.omega.2006.05.001

[44] J. Dréo, A. Pétrowski, P. Siarry and E. Taillard, "Metaheuristics for Hard Optimization," Springer-Verlag, Berlin, 2006.

[45] F. Dugardin, F. Yalaoui and L. Amodeo, "New Multiobjective Method to Solve Re-Entrant Hybrid Flow Shop Scheduling Problem," European Journal of Operational Research, Vol. 203, No. 1, 2010, pp. 22-31. doi:10.1016/j.ejor.2009.06.031

[46] X. R. Gandibleux and M. Ehrgott, “(1984-2004)-20 Years of Multiobjective Metaheuristics, But What About the Solution of Combinatorial Problems with Multiple Objectives?" Lecture Notes in Computer Science, Vol. 3410,
2005, pp. 33-46.

[47] H. Katagiri, M. Sakawa, K. Kato and I. Nishizaki, "A Fuzzy Random Multi-Objective 0-1 Programming Based on the Expectation Optimization Model Using Possibility and Necessity Measures," Mathematical and Computer Modelling, Vol. 40, No. 3-4, 2004, pp. 530-539. doi:10.1016/j.mcm.2003.08.007

[48] J. Dupačová, "Applications of Stochastic Programming: Achievements and Questions," European Journal of Operational Research, Vol. 140, No. 2, 2002, pp. 281-290. doi:10.1016/S0377-2217(02)00070-X

[49] J. Mayer, "Stochastic Linear Programming Algorithms," Overseas Publishers Association, 1984.

[50] R. Slowinski and J. Teghem, "Stochastic versus Fuzzy Approaches to Multiobjective Mathematical Programming under Uncertainty," Kluwer Academic Publishers, Dordrecht, 1990. doi:10.1007/978-94-009-2111-5

[51] I. I. Croley, E. R. Thomas and N. R. Kuchibhotla, "Multiobjective Risks in Reservoir Operation," Water Resources Research, Vol. 15, No. 4, 1979, pp. 807-814. doi:10.1029/WR015i004p00807

[52] A. Goicoechea, L. Duckstein and M. Fogel, "Multiple Objectives under Uncertainty: An Illustrative Application of Protrude," Water Resources Research, Vol. 15, No. 2, 1979, pp. 203-210. doi:10.1029/WR015i002p00203

[53] H. Fazlollahtabar and I. Mahdavi, "Applying Stochastic Programming for Optimizing Production Time \& Cost in an Automated Manufacturing System," International Conference on Computers \& Industrial Engineering, Troyes, 6-9 July 2009, pp. 1226-1230.

[54] A. Alarcon-Rodriguez, G. Ault and S. Galloway, "Multiobjective Planning of Distributed Energy Resources: A Review of the State-of-the-Art," Renewable \& Sustainable Energy Reviews, Vol. 14, No. 5, 2010, pp. 1353-1366. doi:10.1016/j.rser.2010.01.006

[55] M. Bravo and I. Gonzalez, "Applying Stochastic Goal Programming: A Case Study on Water Use Planning," European Journal of Operational Research, Vol. 196, No. 39, 2009, pp. 1123-112. doi:10.1016/j.ejor.2008.04.034

[56] T. Z. Caner and Ü. A. Tamer, "Tactical Level Planning in Float Glass Manufacturing with Co-Production, Random Yields \& Substitutable Products," European Journal of Operational Research, Vol. 199, No. 1, 2009, pp. 252261.

[57] J. Teghem, "Strange an Interactive Method for Multiobjective Stochastic Linear Programming and StrangeMomix Its Extension to Integer Variables," In: R. Slowinski and J. Teghem, Eds., Stochastic versus Fuzzy Approaches to Multiobjective Mathematical Programming under Uncertainty, Kluwer Academic, Dordrecht, 1990. doi:10.1007/978-94-009-2111-5_6

[58] J. Teghem, D. Dufrane, M. Thauvoye and P. L. Kunsch, "Strange: An Interactive Method for Multi-Objective Linear Programming under Uncertainty," European Journal of Operational Research, Vol. 26, No. 1, 1986, pp. 65-82. doi:10.1016/0377-2217(86)90160-8

[59] J. Teghem and P. Kunsch, "Application of Multiobjective 
Stochastic Linear Programming to Power Systems Planning," Engineering Costs and Production Economics, Vol. 9, No. 13, 1985, pp. 83-89. doi:10.1016/0167-188X(85)90013-8

[60] V. Vahidinasab and S. Jadid, "Stochastic Multiobjective Self-Scheduling of a Power Producer in Joint Energy \& Reserves Markets," Electric Power Systems Research, Vol. 80, No. 7, 2010, pp. 760-769. doi:10.1016/j.epsr.2009.11.007

[61] Z. Wang, X.-P. Jia and L. Shi, "Optimization of Multi-Product Batch Plant Design under Uncertainty with Environmental Considerations," Clean Technologies and Environmental Policy, Vol. 12, No. 3, 2009, pp. 273-282.

[62] J. R. Birge and F. Louveax, "Introduction to Stochastic Programming," Springer, New York, 1997.

[63] P. Kall and S. W. Wallace, "Stochastic Programming," John Wiley \& Sons Inc., New York, 1994.

[64] A. Prekopa, "Stochastic Programming," Kluwer Academic Publishers, Dordrecht, 1995.

[65] J. von Neumann and O. Morgenstern, "Theory of Games and Economic Behavior," Princeton University Press, Princeton, 1953.

[66] K. Tammer, "Relations between Stochastic and Parametric Programming for Decision Problems with a Random Objective Function," Optimization, Vol. 9, No. 4, 1978, pp. 523-535.

[67] B. O. Bereanu, "On Stochastic Linear Programming I: Distribution Problems, a Single Random Variable," Revue Roumaine de Mathematiques Pures et Appliqueés, Vol. 8, No. 4, 1963, pp. 683-697.

[68] S. Kataoka, "On Stochastic Programming II: A Preliminary Study on a Stochastic Programming Model," Hitotsubashi Journal of Arts Sciences, Vol. 2, 1963, pp. 3644.

[69] I. M. Stancu-Minasian and S. Tigan, "The Vectorial Minimum Risk Problem," Proceedings of the Colloquium on Approximation and Optimization, Cluj-Napoca, 1984, pp. 321-328.

[70] M. S. Bazaraa, J. J. Goode and C. M. Shetty, "Constraint Qualifications Revisited," Management Science, Vol. 18, No. 9, 1972, pp. 567-573. doi:10.1287/mnsc.18.9.567

[71] D. P. Bertsekas, "Nonlinear Programming," Athena Scientific, Belmont, 1999.

[72] P. Kall, "Stochastic Linear Programming," Springer-Verlag, Berlin, 1972.

[73] R. Caballero, E. Cerdà, M. M. Muñoz and L. Rey, "Stochastic Approach versus Multiobjective Approach for Obtaining Efficient Solutions in Stochastic Multiobjective Programming Problems," European Journal of Operational Research, Vol. 158, No. 3, 2004, pp. 633-648. doi:10.1016/S0377-2217(03)00371-0

[74] R. Caballero, E. Cerdà, M. M. Muñoz, L. Rey and I. M. Stancu-Minasian, "Efficient Solution Concepts and Their Relations in Stochastic Multiobjective Programming," Journal of Optimization Theory \& Applications, Vol. 110, No. 1, 2001, pp. 53-74. doi:10.1023/A:1017591412366
[75] S. P. Canto, "Application of Benders' Decomposition to Power Plant Preventive Maintenance Scheduling," European Journal of Operational Research, Vol. 184, No. 2, 2011, pp. 759-777. doi:10.1016/j.ejor.2006.11.018

[76] I. Deák, "Two Stage Stochastic Problems with Correlated Normal Variables: Computational Experiences," Annals of Operations Research, Vol. 142, No. 1, 2006, pp. 79-97. doi:10.1007/s10479-006-6162-2

[77] J. L. Higle and S. Sen, "Stochastic Decomposition," Kluwer Academic Publishers, Dordrecht, 1996.

[78] A. Charnes and W. W. Cooper, "Deterministic Equivalents for Optimizing and Satisfying under Chance Constraints," Operations Research, Vol. 11, No. 1, 1963, pp. 18-39. doi:10.1287/opre.11.1.18

[79] J. Linderoth, A. Shapiro and S. Wright, "The Empirical Behaviour of Sampling Methods for Stochastic Programming," Annals of Operations Research, Vol. 142, No. 1, 2006, pp. 215-241. doi:10.1007/s10479-006-6169-8

[80] G. Ch. Pflug, "Optimization of Stochastic Models," Kluwer Academic Publishers, Dordrecht, 1996.

[81] G. Ch. Pflug, "Optimization of Stochastic Models: The Interface between Simulation and Optimization," Kluwer Academic Publishers, Dordrecht, 1996.

[82] J. Castro, "A Stochastic Programming Approach to Cash Management in Banking," European Journal of Operational Research, Vol. 192, No. 3, 2009, pp. 963-974. doi:10.1016/j.ejor.2007.10.015

[83] B. Aouni and D. L. Torre, "A Generalized Stochastic Goal Programming Model," Applied Mathematics \& Computation, Vol. 215, No. 12, 2010, pp. 4347-4357. doi:10.1016/i.amc.2009.12.065

[84] E. Ballestero, I. Gonzalez, A. Benito and M. Bravo, "Stochastic Goal Programming Approach to Solve a Portfolio Selection with Multiple Uncertain Scenarios," 7th Conference on Multi-objective Programming and Goal Programming, Toures, 12-14 June 2006.

[85] A. Chen, J. Kim, S. Lee and Y. Kim, "Stochastic Multiobjective Models for Network Design Problem," Expert Systems with Application, Vol. 37, No. 2, 2010, pp. 16081619. doi:10.1016/i.eswa.2009.06.048

[86] R. Minciardi, M. Robba and R. Sacile, "Decision Models for Sustainable Groundwater Planning and Control," Control Engineering Practice, Vol. 15, No. 8, 2007, pp 1013-1029. doi:10.1016/j.conengprac.2006.10.017

[87] M. M. Muñoz and F. Ruiz, "ISTMO: An Interval Reference Point-Based Method for Stochastic Multiobjective Programming Problems," European Journal of Operational, Vol. 197, No. 1, 2009, pp. 25-35. doi:10.1016/j.ejor.2008.06.012

[88] L. Paquete and T. Stützle, "Design and Analysis of Stochastic Local Search for the Multiobjective Traveling Salesman Proble," Computers and Operations Research, Vol. 36, No. 9, 2009, pp. 2619-2631. doi:10.1016/j.cor.2008.11.013

[89] A. Shing, B. S. Minsker and A. J. Valochi, "An Interac- 
tive Multi-Objective Optimization Framework for Groundwater Inverse Modeling," Advances in Water Resources, Vol. 31, No. 10, 2008, pp. 1269-1283. doi:10.1016/j.advwatres.2008.05.005

[90] M. Mortazavi, “A Goal Programming Model with Stochastic Goal Constraints," Department of Mathematical Sciences, Eastern New Mexico University, Portales, 2003.

[91] B. Aouni, F. Ben Abdelaziz and J.-M. Martel, "Decisionmaker's Preferences Modelling in the Stochastic Goal Programming," European Journal of Operational Research, Vol. 162, No. 3, 2005, pp. 610-618. doi:10.1016/j.ejor.2003.10.035

[92] E. Erdoğan and G. Iyengar, "On Two-Stage Convex Chance Constrained Problems," Mathematical Methods of Operations Research, Vol. 65, No. 1, 2007, pp. 115-140. doi:10.1007/s00186-006-0104-2

[93] W. K. Klein Haneveld and M. H. van der Vlerk, "Integrated Chance Constraints: Reduced Forms and an Algorithm," Computational Management Science, Vol. 3, No. 4, 2006, pp. 245-269. doi:10.1007/s10287-005-0007-3

[94] R. Caballero, E. Cerdà, M. M. Muñoz and L. Rey, "Analysis and Comparison of Some Solution Concepts for Stochastic Multiobjective Programming Problems," Sociedad de Estadistica Investigacion Operativa Top, Vol. 10, No. 1, 2002, pp. 101-123.

[95] J. Teghem and P. L. Kunsch, "Multiobjective Decision Making under Uncertainty: An Example for Power System," In: Y. Y. Haimes and V. Chankong, Eds., Decision Making with Multiple Objectives, Springer-Verlag, Berlin, 1985, pp. 443-456.

[96] F. Ben Abdelaziz, B. Aouni and R. E. Fayedh, "Multiobjective Stochastic Programming for Portfolio Selection," European Journal of Operational Research, Vol. 177, No. 3, 2007, pp. 1811-1823. doi:10.1016/j.ejor.2005.10.021

[97] L. F. Escudero, P. V. Kamesam, A. J. King and R. J.-B. Wets, "Production Planning via Scenario Modelling," Annals of Operations Research, Vol. 43, No. 6, 2009, pp. 309-335. doi:10.1007/BF02025089

[98] J. Aghaei, H. A. Shayanfar and N. Amjady, "Joint Market Clearing in a Stochastic Framework Considering Power System Security," Applied Energy, Vol. 86, No. 9, 2009, pp. 1675-1682. doi:10.1016/j.apenergy.2009.01.021

[99] N. Geng, Z. Jiang and F. Chen, "Stochastic Programming Based Capacity Planning for Semiconductor Wafer Fab with Uncertain Demand \& Capacity," European Journal of Operational Research, Vol. 198, No. 3, 2009, pp. 899908. doi:10.1016/j.ejor.2008.09.029

[100] C. S. Nembou and B. A. Murtagh, "A Chance-Constrained Programming Approach to Modelling HydroThermal Electricity Generation in Papua-New Guinea," Asia-Pacific Journal of Operational Research, Vol. 13, No. 2, 1996, pp. 105-114.
[101] R. Pal and I. Bose, “An Optimization Based Approach for Deployment of Roadway Incident Response Vehicles with Reliability Constraints," European Journal of Operational Research, Vol. 198, No. 2, 2009, pp. 452-463. doi:10.1016/j.ejor.2008.09.010

[102] A. Castillo, T. B. Joro and Y. Y. C. Li, "Workforce Scheduling with Multiple Objectives," European Journal of Operational Research, Vol. 196, No. 1, 2009, pp. 162170. doi:10.1016/j.ejor.2008.02.038

[103] P. L. Kunsch, "Application of Strange to Energy Studies," In: R. Slowinski and J. Teghem, Eds., Stochastic versus Fuzzy Approaches to Multiobjective Mathematical Programming under Uncertainty, Kluwer Academic Publishers, Dordrecht, 1990. doi:10.1007/978-94-009-2111-5 7

[104] U. K. Bhattacharya, "A Chance Constraints Goal Programming Model for the Advertising Planning Problem," European Journal of Operational Research, Vol. 192, No. 2, 2009, pp. 382-395. doi:10.1016/j.ejor.2007.09.039

[105] C. Changchit and P. Terrell, "A Multiobjective Reservoir Operation Model with Stochastic Inflows," Computers and Industrial Engineering, Vol. 24, No. 2, 1993, pp. 303-313. doi:10.1016/0360-8352(93)90016-Q

[106] X. Ji, S. Zhu, S. Wang and S. Zhang, "A Stochastic Linear Goal Programming Approach to Multistage Portfolio Management Based on Scenario Generation via Linear Programming," IIIE Transactions, Vol. 37, No. 10, 2005, pp. 957-969. doi:10.1080/07408170591008082

[107] A. J. Keown, “A Chance-Constrained Goal Programming Model for Bank Liquidity Management," Decision Sciences, Vol. 9, No. 1, 1978, pp. 93-106. doi:10.1111/j.1540-5915.1978.tb01369.x

[108] A. J. Keown and J. D. Martin, “A Chance-Constrained Goal Programming Model for Working Capital Management," The Engineering Economist, Vol. 22, No. 3, 1977, pp. 153-174. doi: 10.1080/00137917708965174

[109] M. Tamiz, R. Hasham, D. F. Jone, B. Hesni and E. K. Fargher, "A Two Staged Goal Programming Model for Portfolio Selection," Lecture Notes in Economics and Mathematical Systems, Vol. 432, 1996, pp. 286-299.

[110] R. A. Howard, "Decision Analysis: Practice and Promis," Management Science, Vol. 34, No. 6, 1998, pp. 679-695. doi: $10.1287 / \mathrm{mnsc} .34 .6 .679$

[111] M. W. Kirby, "Paradigm Change in Operations Research: Thirty Years of Debate," Operations Research, Vol. 55, No. 1, 2007, pp. 1-13. doi:10.1287/opre.1060.0310

[112] M. K. Luhandjula, "Optimization under Uncertainty," Fuzzy Sets and Systems, Vol. 146, No. 2, 2004, pp. 187203. doi:10.1016/j.fss.2004.01.002

[113] M. K. Luhandjula and A. S. Adeyefa, "Multiobjective Problems with Fuzzy Random Coefficients," Advances in Fuzzy Sets \& Systems, Vol. 7, 2010, pp. 1-16. 